\title{
The town in my mind: How place attachment and identification are linked to place perception
}

\author{
Chiara Rollero \\ University of Turin

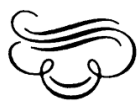 \\ Abstract
}

The relationship between individuals and environment implies an affective and a cognitive dimension, i.e. place attachment and place identification. While predictors of these two constructs have been extensively studied, their relationship with place perception has received less attention. The research here presented aimed to explore the subjective perceptions of the locality where one lives. Such perceptions were considered in relation to the degree of place attachment and social identification with inhabitants, and taking into account: sex, place of birth, length of residence, and location of meaningful relationships. 403 Italian undergraduates participated in the research. Results showed that semantic contents related to place perception are described in accordance to different levels of attachment and identification. Moreover, those who have experienced a relocation show a more stereotypical perception of the town than individuals who are studying in the place where they were born.

Keywords: Place attachment, place identification, place perception.

\section{La ciudad en mi mente: cómo el apego al lugar y la identificación se relacionan con la percepción del lugar}

\begin{abstract}
Resumen
La relación entre las personas y el entorno implica afecto y cognición, es decir, apego al lugar e identificación con lugar. Mientras los indicadores de estos dos conceptos se han estudiado ampliamente, su relación con la percepción del lugar ha recibido menos atención. La investigación presentada explora las percepciones subjetivas de la ciudad en la que se vive, en relación con el grado de apego al lugar e identificación social con los habitantes y teniendo en cuenta sexo, lugar de nacimiento, tiempo de residencia y ubicación de las relaciones significativas. 403 estudiantes universitarios italianos participaron en el estudio. Los resultados mostraron que los contenidos semánticos relacionados con la percepción lugar se describen de acuerdo a los diferentes niveles de apego e identificación. Asimismo, las personas que han experimentado un traslado muestran una percepción más estereotipada de la ciudad que las personas que están estudiando en el lugar donde nacieron.

Palabras clave: Apego al lugar, identificación con el lugar, percepción del lugar..
\end{abstract}

Authors' Address: Department of Psychology, University of Turin, Via Verdi 10, 10124 Torino - Italy. E-mail: chiara.rollero@unito.it

Manuscript received: June 9, 2013. Accepted: July 17, 2013. 
The relationship between individuals and their environment has two linked but different aspects: an affective dimension, that is the emotional bond toward places (place attachment), and a cognitive dimension, related to the cognitions about the self as a member of a physical space (place identification) (Hernández, Hidalgo, Salazar-Laplace, \& Hess, 2007; Rollero \& De Piccoli, 2010a).

Specifically, place attachment can be defined as the affective link that people establish with specific environments, where they have a propensity to remain and where they feel comfortable and safe (Hidalgo \& Hernández, 2001). It encourages greater freedom of behaviour, exploration, confidence and affective responsiveness within the local community (Fried, 2000).

Moreover, place can be considered a social category and thus subject to the same rules as a social identification. Therefore, place identification expresses membership of a group of people who are defined by their location (TwiggerRoss \& Uzzell, 1996). Indeed, it applies specifically to the aspects of identity and those of the self-categorization on the basis of the membership to a locally defined group.

If factors affecting place attachment and place identification have been largely studied (see, for example, Hidalgo \& Hernández, 2001; Lewicka, 2005; Rollero \& De Piccoli, 2010a), less attention has been deserved to the relation between these two constructs and the environmental perception. The exploration of such issue seems to be particularly relevant. As Félonneau argues (2004), representations of the place are grounded in social experiences and also constitute a deep expression of the subjectivity of the person. This is the reason why they need to be included in the analysis to measure their influence on the relationship between people and their environment. Indeed, individuals may attribute to the same environment different features and meanings, in accordance with their level of place attachment and identification (Rollero \& De Piccoli, 2010a; Stedman, 2002). In other words, the place perception relies not only on the information available in the environment but also on the perceiver's characteristics. As Brown, Perkins and Brown (2003) found, place attachment seems to be higher for residents who perceive fewer incivilities and less physical decline on their block. A strong bond with a place can also favour positive images in terms of pleasantness, healthy and safeness (Billig, 2006).

The study here presented aimed at deeper investigating place perception. Specifically, the interest lied in the representations of the living town individuals express when they are involved in a free-association task ${ }^{1}$. Such subjective perceptions were considered not only in relation to the degree of place attachment and social identification with inhabitants, but also in respect to individuals' sex, place of birth, length of residence, and location of significant relationships.

\section{Method}

\section{Participants}

Participants were 403 undergraduates (70.2\% females) attending the University of Turin. Age ranged from 18 to 30 years, with a mean age of 21.43 $(S D=3.68)$. The $77.2 \%$ of the sample came from different parts of Italy and the remaining $22.8 \%$ was going to University in the home-town. Turin is a town of about 900000 inhabitants in the North-West of Italy. Fiat, the biggest Italian multinational company, has its corporate headquarters there. In February 
2006 Turin hosted the Winter Olympic Games, an event that contributed to its international fame.

\section{Instruments and procedure}

Data were gathered by a self-reported questionnaire which took about 15 minutes to be filled in, divided into 5 sections:

1. A free association of words with the word "Turin" in order to investigate the subjective images of the town of residence. Participants were requested to answer the statement: "Think of the town of Turin and write the first five words that come to your mind".

2. The Residential Attachment Scale (Bonaiuto, Fornara, Aiello \& Bonnes, 2002), a unifactorial Italian scale created to measure place attachment, made up of 8 items (e.g. "I would like to live in another town"; "For me leaving Turin would be really hard") (Cronbach's alpha $=.79$ ).

3. The Identification with a Psychological Group Scale (Mael \& Tetrick, 1992), a unifactorial scale used to assess the identification towards the social group of inhabitants (Torinesi), made up of 10 items (e.g. "When someone criticizes Torinesi, I feel personally insulted"; "When I talk about Torinesi usually I say we and not they"; "The limits referred to Torinesi are also my limits") (Cronbach's alpha $=.88)$.

5. A socio-demographical section and three items on: 1) the location of the most significant interpersonal relationships: "Where do your close friends live?" (scored on a three-point scale: 1. "Most of them don't live in Turin", 2. "About half of them live in Turin", 3. "Most of them live in Turin"); 2) the place of birth; and 3) the length of residence.

\section{Data analysis}

The free associations of words were analyzed by software Alceste 4.6 (Reinert, 1986). The Alceste software package is a computer-based application combining textual and statistical analysis. It performs a descendent cluster analysis based on the lexical co-occurrences among the responses of participants to the free association of words. The result is a hierarchy of classes, which can be represented in a tree diagram. Selecting the characteristic (property on a variable) to distinguish subjects, through the $\chi^{2}-$ test the software compares the within-cluster occurrence of the words with their overall occurrence on the total of responses: the highest $\chi^{2}$ values correspond to the most typical words of the subjects in that cluster (with the minimum $\chi^{2}$ value for selection set at 2.13 , below which the level of statistical significance fails to reach the $10 \%$ level, using the standard $\chi^{2}$ table with 1 degree of freedom) (for an application of this method in the field of environmental psychology, see Rollero \& De Piccoli, 2010a). Moreover, by means of the same statistical analysis, Alceste makes it possible to test the association between clusters and particular characteristics of participants (considered as categorical variables). In the present study, we selected the following variables: sex, place of birth, length of residence (less than one year, between 1 and 5 years, more than 5 years), location of significant relationships, place attachment and social identification with inhabitants.

\section{Results}

We collected 2009 words in reply to the free association task about the perception of the city of Turin: amongst these words, there were 883 


\section{Estudios de Psicología, 2013, 34 (3), pp. 309-314}

different forms and 541 hapax (i.e. words occurring just once in the whole textual corpus, in this case $26.93 \%$ of the whole corpus). The most frequent words were: $\operatorname{Mole}^{2}(N=125)$, University $(N=104)$, traffic $(N=85)$, Olympic Games $(N=75)$, chaotic $(N=61)$, beautiful $(N=47)$, big $(N=$ $40)$, Po river $(N=36)$, fun $(N=35)$, grey $(N=33)$, culture $(N=30)$, art $(N=27)$.

The cluster analysis enabled a good proportion of the responses (the 84.73\%) to be classified into 4 classes. The first two classes were focused on objects, places and events, whereas the last two classes pertained to those participants who associated the town to adjectives and features (both in a positive and in a negative conception).

Specifically (Table I), cluster 1 (30.48\% of the classified responses) conveyed an image of the town - expressed mainly through nouns - mainly as chaotic, characterized by smog, traffic, cars, crowd and immigrants. This cluster contained a significantly high number of responses given by subjects born elsewhere, with a medium length of residence and by low identifiers. In cluster 2 , the largest, $(31.47 \%$ of the classified responses) the perception of the town was instead focused on the most stereotypic events and places (i.e. Mole, Olympic Games, Fiat, the main station Porta Nuova). Even this class was associated to students coming from other parts of Italy.

TABLE I

The perception of Turin: characteristic words and illustrative variables of cluster 1 and cluster 2

\begin{tabular}{llll}
\hline Cluster 1 & \multicolumn{2}{l}{ Cluster 2 } & \\
\hline Words & $\chi^{2}$ & Words & $\chi^{2}$ \\
\hline Grey & 90.11 & Mole & 141.63 \\
Smog & 53.84 & Olympic Games & 90.68 \\
Chaos & 43.15 & Po river & 72.70 \\
Cars & 31.98 & University & 39.96 \\
Traffic & 29.80 & Castello square & 31.80 \\
Crowd & 29.56 & Fiat & 22.17 \\
Immigrants & 14.76 & Porta Nuova & 13.30 \\
$*$ Place of birth: elsewhere & 2.35 & $*$ Place of birth: elsewhere & 8.13 \\
$*$ Social identification: low & 2.35 & & \\
* Length of residence: 1-5 years & 2.04 & & \\
\hline
\end{tabular}

The last two classes pertained to the characteristics of the town, expressed through adjectives (Table II). Cluster 3 (18.24\% of the classified corpus), which was similar to Cluster 1 , showed an explicit negative conception of the town, described as polluted, chaotic, noisy and sad. This perception was expressed mainly by low identified and low attached subjects, who come from other parts of Italy and who maintain the most significant relationships elsewhere. An opposite description of Turin came from cluster $4(19.70 \%$ of the classified responses), where the town was perceived as attractive, friendly, full of life and culture. This class contained the words produced by high attached and high identified students, as well as by long lasting residents. 
TABLE II

The perception of Turin: characteristic words and illustrative variables of cluster 3 and cluster 4

\begin{tabular}{lllc}
\hline Cluster 3 & \multicolumn{2}{l}{ Cluster 4} & $\chi^{2}$ \\
\hline Words & $\chi^{2}$ & Words & 92.41 \\
\hline Polluted & 69.11 & Attractive & 87.85 \\
Big & 51.32 & Culture & 75.71 \\
Chaotic & 49.30 & Friendly & 73.66 \\
Cold & 41.50 & Young & 58.98 \\
Noisy & 40.27 & Artistic & 33.54 \\
Sad & 27.39 & Smart & 33.06 \\
Crowdy & 27.39 & Full of life & 18.56 \\
& & Beautiful & 4.01 \\
* Place attachment: low & 4.60 & * Length of residence: $>$ 5 years & 2.87 \\
* Place of birth: elsewhere & 3.73 & * Significant relationships: in town & 2.70 \\
* Significant relationships: elsewhere & 3.00 & * Place attachment: high & 2.56 \\
* Social identification: low & 2.35 & * Social identification: high & 2.56 \\
\hline
\end{tabular}

\section{Discussion}

The present research was aimed at describing the perception of the town, in relation to the degree of place attachment and identification with the inhabitants. We examined the representation of the town in terms of the semantic contents produced, showing differences according to the level of place attachment and identification, to place of birth, length of residence, and location of the most significant relationships. Specifically, high attached and high identified individuals underline the positive and appreciable features of the town by means of many adjectives that are affectively meaningful. In other words, they not only describe the place positively, but also express their affective bond.

In a similar way, low attached and low identified people give a representation which is affectively connoted, although in a negative tone. Indeed, the town is depicted through adjectives pertaining emotions (i.e. sad), which refer to many unenthusiastic characteristics of the place. We are dealing with subjects that were not born in the town and that maintain their significant relationships elsewhere. As literature has shown, social relationships are essential to the development of place attachment, as well as length of residence, which affects both place attachment and identification (Hernández et al., 2007; Lewicka, 2005; Rollero \& De Piccoli, 2010a).

Individuals born elsewhere show also two other kinds of representation, one connected to stereotypes and the other to negative characteristics of the town. This last, focused on disturbing elements (cars, chaos, smog, crowd), is expressed also by low identified subjects with a short length of residence. The other image - focused on Mole, Olympic Games, Fiat, Castello square - is instead connected to a "surface" description of the place, more similar to a touristic perception than to a resident's one.

In line with Stedman (2002), our results suggest that the same environment is attributed different features and meanings by diverse individuals. In other words, the place perception relies not only on the information available in the environment but also on the perceiver's characteristics, such as place 


\section{Estudios de Psicología, 2013, 34 (3), pp. 309-314}

attachment, identification, place of birth and length of residence. In parallel, the link between people and places is based also on cognitions and meanings attributed to the spatial setting: people ascribe meaning to landscapes and places and in turn become attached to the meaning (Stedman, 2002). This is particularly relevant when specific populations, i.e. individuals experiencing relocation, or specific places are considered: how can people develop attachment to a negatively perceived place? Does an appealing town or neighbourhood help cognitive and emotional links? And, vice versa, can an affective link lead to a more positive perception of a not so pleasing environment?

In sum, the experience of living in a place is a complex and multifaceted phenomenon that can be explored taking into account different aspects, such as the affective dimensions, the cognitive elements, as well as the representation and images connected to environment. This is relevant per se, but it is still more important as literature has largely demonstrated that a positive relationship with the living place increases and sustains well-being and life satisfaction (Cicognani et al., 2008; Fried, 1963; Rollero \& De Piccoli, 2010b).

\section{Notes}

${ }^{1}$ This method, compared to the interview or to adjective checklists, underlies more spontaneous - and thus less controlled - processes and permits an easier and faster access to the images people have in mind.

${ }^{2}$ Mole is the name of a historical monument, which is the symbol of the city.

\section{References}

BILLIG, M. (2006). Is my home my castle? Place attachment, risk perception, and religious faith. Environment and Behavior, 38, 248-265.

Bonaiuto, M., Fornara, F., Aiello, A., \& Bonnes, M. (2002). La qualità urbana percepita. In M. Prezza, \& M. Santinello (Eds.), Conoscere la comunità (pp. 133-160). Bologna: Il Mulino.

Brown, B., Perkins, D., \& Brown, G. (2003). Place attachment in a revitalizing neighbourhood: Individual and block levels of analysis. Journal of Environmental Psychology, 23, 259-271.

Cicognani, E., Pirini, C., Keyes, C., Joshanloo, M., Rostami, R., \& Nosratabadi, M. (2008). Social participation, sense of community and social well-being: A study on American, Italian and Iranian University students. Social Indicators Research, 89, 97-112.

FÉLONNEAU, M. L. (2004). Love and loathing of the city: Urbanophilia and urbanophobia, topological identity and perceived incivilities. Journal of Environmental Psychology, 24, 43-52.

Fried, M. (1963). Grieving for a lost home. In L. J. Duhl (Ed.), The urban condition (pp. 151-171). New York: Basic Books.

Fried, M. (2000). Continuities and discontinuities of place. Journal of Environmental Psychology, 20, 193-205.

Hernández, B., Hidalgo, M. C., Salazar-Laplace, M. E., \& Hess, S. (2007). Place attachment and place identity in natives and non-natives. Journal of Environmental Psychology, 27, 310-319.

Hidalgo, M. C., \& Hernández, B. (2001). Place attachment: Conceptual and empirical questions. Journal of Environmental Psychology, 21, 273-281.

LEWICKA, M. (2005). Ways to make people active: The role of place attachment, cultural capital, and neighbourhood ties. Journal of Environmental Psychology, 25, 381-395.

MAEL, F. A., \& TETRICK, L. E. (1992). Identifying Organizational Identification. Educational and Psychological Measurement, 52, 813-824.

REINERT, M. (1986). Un logiciel d'analyse lexicale: ALCESTE. Les cabiers de l'Analyse des Données, 4, 471-484.

Rollero, C., \& De Piccoli, N. (2010a). Place attachment, identification and environment perception: An empirical study. Journal of Environmental Psychology, 30, 198-205.

Rollero, C., \& De PicColi, N. (2010b). Does place attachment affect social well-being? European Review of Applied Psychology, 60, 233-238.

Stedman, R. C. (2002). Toward a social psychology of place: Predicting behavior from place-based cognitions, attitude, and identity. Environment and Behavior, 34, 405-425.

Twigger-Ross, C. L., \& Uzzeld, D. L. (1996). Place and identity process. Journal of Enviromental Psychology, $16,205-220$. 